\title{
Determinants of Early Complementary Feeding Practices among Children below 6 Months Old in Kisii Level 6 Hospital in Kisii County
}

\author{
Abdub Halakhe* \\ Department of Nutrition, Kenya Medical Training College-Karen Campus, Kenya \\ *Corresponding Author: Abdub Halakhe, Department of Nutrition, Kenya Medical Training College-Karen Campus, Kenya.
}

Received: June 11, 2019; Published: July 19, 2019

DOI: $10.31080 /$ ASNH.2019.03.0372

\begin{abstract}
Scientific evidence on infant and young child feeding practices from developing countries show that progress is possible when effective strategies and sufficient resources are applied. However, significant gaps in early complementary feeding continue to undermine child health. There is limited scientific data on early complementary feeding practices and its relation to nutrition status of children below 6 months in Kisii County. A number of children in this study were affected with under nutrition. The study will use simple random sampling to identify respondents. This is a cross-sectional study that will use an interviewer administered semistructured questionnaire for data collection. The data will be collected from 60 respondents. The aim of the study will be to assess the Determinants of early complementary feeding among children below 6 months in Kisii level 6 hospital, Kisii County.
\end{abstract}

Keywords: Complementary Feeding; Kisii Level 6; Children

\section{Abbreviations}

ACC/SCN: Administrative Committee on Coordination/Subcommittee on Nutrition United Nations; UNICEF: United Nations Children Fund; KNBS: Kenya National Bureau of Statistics; KDHS: Kenya Demographic Health Survey; WHO: World Health Organization; IYCF: Infant and Young Child Feeding; MIYCN: Maternal Infant and Young Child Nutrition; BFCI: Baby Friendly Community Initiative; BFHI: Baby Friendly Hospital Initiative; GOK: Government of Kenya; NACOSTI: National Commission for Science, Technology and Innovation; EBF: Exclusive Breastfeeding; PAHO: Pan-American Health Organization; MCH: Maternal and Child Health clinic.

\section{Introduction}

Background information

Adequate nutrition during infancy and early childhood is fundamental to the development of each child's full human potential. It is well recognized that the period from birth to two years of age is a critical window for the promotion of optimal growth, health and behavioral development.
Malnutrition is responsible globally for $60 \%$ of deaths among children under 5 years and is often attributed to suboptimal feeding practices (Neil Gupta., et al. 2012) According to CPS/DC/HC (2010), the ideal practice for infants is exclusive breastfeeding for the first 4-6 months of life followed by optimal complimentary and continued breastfeeding. The period of complementary feeding is one of the critical times for preventing malnutrition. At the crucial growth period between 4 to 6 months, more energy is needed. However, when complementary foods are introduced at time it is important to note that the quality and frequency of added feeds will negatively impact breast milk intake [CPS/DC/HC 2010]. Malnutrition in this age affects health later in life. It is scientifically proven that inappropriate feeding practices can have profound consequences on growth and development including survival of infants and children [saha., et al. 2010]. It is estimated that $25 \%$ of all childhood deaths could be prevented by interventions to improve breastfeeding, complementary feeding, zinc and vitamin A nutrition [SCN NEWS 2011]. 
The Government of Kenya deriving from the principles of the joint WHO and UNICEFs global strategy for infant and young child feeding developed in 2014 has implemented a number of strategies aimed at improving IYCF practices in the country. Examples are Maternal Infant and Young Child Nutrition (MIYCN), Baby Friendly Community Initiative (BFCI) and Baby Friendly Hospital Initiative (BFHI) (GOK According to UNICEF (2009a) IYCF practices have improved over the recent past. In the developing world, however, only $39 \%$ of infants less than 6 months are exclusively breastfed and 6\% are never breastfed (Lauer., et al. 2010). In Kenya, according to the Kenya Demographic Health Survey Finding (KDHS 2014), only 32\% of infants less than 6 months are exclusively breastfed showing that complimentary feeding starts early. The level of underweight children in Kenya is high; $8.3 \%$ are wasted, $14.1 \%$ are underweight and $35.2 \%$ are stunted. The high level of under nutrition is due to inappropriate feeding practices in addition to immediate, underlying and basic causes (KNBS and ICF macro, 2010). The prevalence rate of early complementary feeding in Kisii County is 20\%. According to the KDHS 2003; about 70\% of infants in Kenya are started on early complementary foods before the appropriate age of 6 months.

\section{Problem statement}

Giving children complementary food too early could lead to malnutrition and other problems. If given too early the infant may not be able to digest the food properly and it may also reduce intake of breast milk, hence losing out on appropriate energy intake for its growth. Early introduction of complementary food replaces breast milk by food which is usually less nutritious. This increases the risk of diarrhea which is a major cause of morbidity and mortality among infants and young children in developing countries [UNICEF 2010].

Early introduction of complimentary feeding for infants is a common practice in Kisii. Reasons given are still not clear as most mothers and caregivers claim to introduce complementary foods early because they do not have enough milk. Others claim that the baby keeps crying of hunger and colic pains. Some are not completely aware of the benefits of breastfeeding or that breast milk is critically required during the first 6 months.

Purpose of the study

As it is in the title the study is to be carried out as a partial fulfillment for the award of a diploma in community nutrition under the faculty of public health sciences in Kenya Medical Training College and department of nutrition and dietetics.

Justification of the study

The importance of carrying out this study is that the conclusions and recommendations will be used to plan for interventions in prevention of early complementary feeding to children below 6 months hence improve the nutritional status of children in Kisii County and in Kenya.

Objectives

\section{General objectives}

The main objective of this study is to determine factors associated with early introduction of complementary feeding of infants below 6 months attending MCH at Kisii Level 6 Hospital.

Specific objectives

1. To determine the socio-demographic and economic status of the mothers/caregivers of the children below 6 months attending MCH at Kisii Level 6 Hospital.

2. To find out how the feeding practices of mothers affects the children below 6 months in Kisii Level 6 Hospital.

3. To assess maternal knowledge, attitudes and practices of mothers/caregivers about early complementary feeding practices.

4. To determine the age of complementary feeding to children aged 0-6 months

Research questions

1. What is the socio-demographic and economic status of the mothers/caregivers?

2. What are the feeding practices of mothers to children below 6 months?

3. What are the maternal knowledge, attitude and practices of mothers about early complementary feeding?

4. What is the age of complementary feeding to children aged 0-6 months?

Conceptual framework

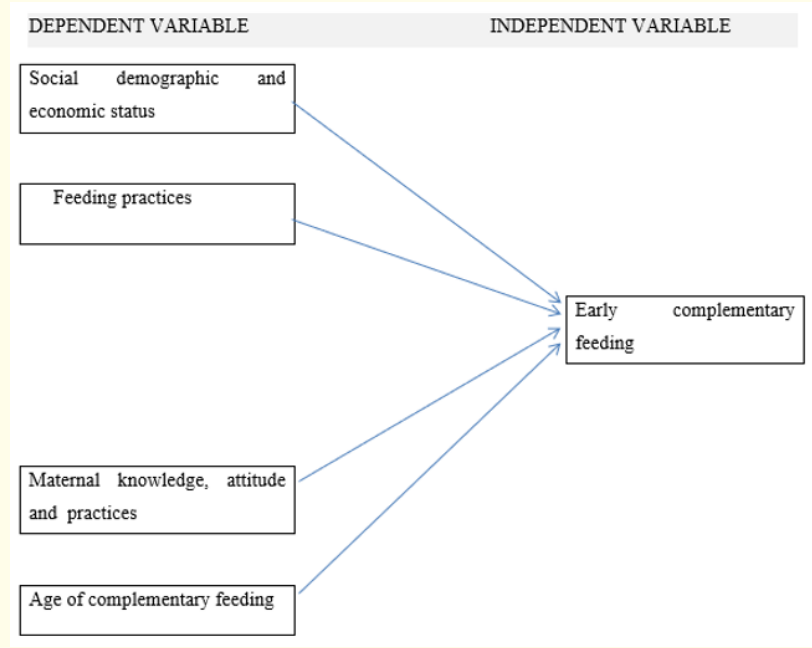

Figure 


\section{Literature Review}

Introduction

Nutrition and feeding practices have great impact in a child's life and on the nutritional status and wellbeing of a child (Malla and Shresta, 2010). Feeding practices like other forms of behavior are reset of complex personal, social cultural and economic influences which are the determinants of the nutritional status of the children. Appropriate feeding practices are important for the growth and development of a child.

In the under nutrition structure (UNICEF 1998) an important underlying determinant of child malnutrition is the care provided to the child. Exclusive Breastfeeding (EBF) for the first 6 months of life followed by optimal complementary feeding are critical public health measures in ensuring good nutritional status and reducing mortality significantly (UNICEF 2009).

Statistics show that most countries in Sub Saharan Africa still have extremely low exclusive breastfeeding rates for infants less than 4 months, with the exception of Ethiopia (55\%), Rwanda (84\%) and Burundi (62\%) (UNICEF, 2005). The proportion of infants' pieinaturely given complementary foods in addition to breastfeeding remains high, ranging approximately between $25 \%$ and $75 \%$ in three quarters of the 33 countries studied.

Factors associated with complementary feeding practices

Socio-demographic and economic factors

\section{Maternal marital status}

According to a study carried out in Ethiopia, findings reveal that child's malnutrition is significantly associated with marital status. It was found out that under-five child malnutrition is higher among unmarried rural and divorced/separated women compared to married ones (Teller., et al. 2000).Similarly, being a married mother was positively associated with good nutritional status among children less than five years in a study carried out in the Volta region of Ghana (Appoh and Krekling, 2005).

Contrary to the above, a study done in Tanzania revealed that mothers who are married were more likely to have undernourished children unlike those that were unmarried perhaps because of the cost of maintaining families hence sometimes, these families fail to produce nutritious supplements to the under-five children (Nyahurucha., et al. 2006).

\section{Maternal education}

Mother's education level affects child's nutrition through her choices and health seeking skills related to nutrition, hygiene, preventive care and disease treatment. Mothers' responsibility to care for herself during pregnancy and her child through the most vulnerable stages of its life significantly affects under-five malnutrition. Several studies have found out that mothers education is associated with good nutrition practices and particularly under-five child nutrition. These studies have pointed out the fact most women with low education spend more time in gardens and feed their children on less nutritious foods. Women who spend more time in gardening get limited time to attend to their children and prepare for them nutritious meals unlike their educated counterparts who normally focus on good child nutrition practices even when they are absent from home most of the time. Education helps mothers gain additional knowledge about the adequate intake of food for their children in terms of correct quantity, quality and frequency. It also determines her income and this helps her access proper nutrition for the child as well as health services (Babatunde and Qalm, 2010; Olwedo., et al. 2008; Webb and Block, 2004; Shrimpton., et al. 2001).

\section{Maternal occupation}

Previous studies have found out that mother's occupation is one of the determinants of under-five malnutrition in most developing countries. According to a study done in Vietnam, findings revealed that children from mothers who were laborers or farmers and housewives had a greater prevalence of stunting, underweight and wasting than those from mothers who worked in office or were housewives (Nguyen and Kam, 2008).

This is because working mothers rarely get time to take care of their children. They also leave their children at home with other siblings who may neglect feeding them following the right frequency (Olwedo., et al. 2008; Rukundo, 1998).A study done on most of the DHS surveys conducted in developing countries especially in Southern Nations, Nationalities and Peoples Region (SNNPR) of Ethiopia showed that under-five children from low economic status households were the most affected by malnutrition (Loaiza, 1997).

A qualitative study on the maternal perceptions on factors contributing to severe under-nutrition among children in Kilifi, Kenya found that mothers mentioned being overwhelmed and unable to 
take care of their children, particularly due to the numerous chores they had to conduct, resulting in them neglecting their children. The women also pointed out that their status in the family affected the nutrition of the child, since they did not control family resources and often lacked the power to implement their knowledge on nutritional needs. Some mentioned that decisions on household food purchases were normally made by husbands or other relatives, rendering the women powerless to include nutritional requirements in the food baskets (Abubakar., et al. 2011).

Feeding practices of mothers status

Importance of breastfeeding

Breastfeeding is an important of a child's growth and development. A major cause of death of in infants and young children is inadequate breastfeeding practices in combination with high levels of disease (Quinn., et al. 2005). The World Health Organization recommends exclusive breastfeeding during the first six months of life for optimal growth and development and health, breastfeeding should continue up to two years or more and nutritionally adequate, safe and appropriately fed complementary foods should be introduced at the age of six months to meet the evolving needs of the growing infant. Exclusive breastfeeding is usually initiated within the first hour of birth; this has a lot of importance, chief among them is the protective effect against gastrointestinal infections, which is not only in developing but also in industrialized countries. According to the WHO growth standards, children who are exclusively breastfed have a more rapid growth in the first six months of life than other infants (WHO, 2008). To achieve successful breastfeeding, expectant mothers and mothers of infants are first of all equipped with information about the benefits of breastfeeding. Mothers are also encouraged to breastfeed on demand and also not to use artificial teats and pacifiers. It is also advisable to give mothers encouragement and support during breastfeeding. For HIV positive mothers, there is a risk that they can transmit HIV to their babies through breastfeeding ; counseling therefore can help them carefully weigh the risks and make an informed decision on which feeding option is best for their babies and at the same time manageable for them.

Duration of breastfeeding and continued breastfeeding

Breastfeeding should begin within the first hour of a baby's life and continue as often and as much as the baby wants. During the first few weeks of a baby's life, they nurse after every two or three hours and as the child gets older they feed less often. WHO recommends breastfeeding exclusively for six months after which the introduction of foods at six months of age, recommendations include continued breastfeeding up to two years and beyond. (Edmond, $\mathrm{K}$ Martines and Bhandari N, 2009).

Breast milk can provide one half or more of a child's energy needs between six months of age, and one third of energy needs and other high quality nutrients between twelve and twenty-four months (Dewey KG, Brown KH,2003). Breast milk continues to provide higher quality nutrients than complementary feeds and also protective factors. Breast milk is a critical source of energy and nutrients during illness (Brown KH., et al. 1990), and reduces mortality among children who are malnourished (Briend A, Bari A, 1989; Mobak., et al. 1994). Children tend to breastfeed less often when complementary foods are introduced, so breastfeeding needs to be actively encouraged to sustain breast milk intake. The nutritional impact of breastfeeding is most evident during periods of illness, when the child's appetite for other foods decreases but breast milk intake is maintained (Brown., et al. 1990). It thus plays a key role in preventing dehydration and providing nutrients required for recovery from infections like anemia and malnutrition.

\section{Challenges of complementary feeding}

Early complementary feeding

A sizeable number of observational studies and randomized trials have failed to identify any benefit of complementary foods for infant growth before 6 months of age, even in low birth weight term infants. By contrast, several studies have documented a twofold or greater risk of enteric and other infections when these foods are provided before 6 months (Brown, 2000).

The national infant feeding policy in Kenya requires that children are exclusively breast fed for six months. This aims at protecting the children from getting exposed to infection before they build up their immune mechanisms, since early introduction of complementary foods in an infant's diet exposes the child to disease causing conditions and is likely to result in infections and increased risk of diarrhea.

However, the status on feeding practices in Kenya shows that a large proportion of children are introduced to complementary foods as early as two weeks after birth, $44 \%$ are given other milk, $19 \%$ are given porridge and $12 \%$ are fed on water and sugar solution (UNICEF and GOK 1998).

Citation: Abdub Halakhe. "Determinants of Early Complementary Feeding Practices among Children below 6 Months Old in Kisii Level 6 Hospital in Kisii County". Acta Scientific Nutritional Health 3.8 (2019): 84-94. 
Onayade in a comparative prospective study in Nigeria to compare the growth and illness pattern of infants who were exclusively breast fed for six months with those of infants commenced on complementary feeding before the age of six months found that early introduction of complementary foods did not provide any advantages in terms of weight gain but rather was frequently associated with illness episodes and growth faltering (Onayade, 2004).

Several studies carried out in developing countries show that the early introduction of complementary foods increases infant morbidity and mortality, as a result of the reduced ingestion of protective factors present in breast milk, in addition to the fact that complementary foods are an important source of contamination for infants. From the nutritional view point, the early introduction of complementary foods can bring some disadvantages since these foods in addition to replacing part of bicast milk; often have a lower nutritional value than breast milk, e.g. foods that are bulky or extremely diluted (Monte and Giugliani, 2004).

Moreover, the early introduction of complementary foods shortens the duration of breastfeeding, inhibits the uptake of important nutrients found in breast milk such as iron and zinc and reduces the efficiency of lactation in preventing new pregnancies. More recently the early introduction of complementary foods has been associated with the development of atopic diseases.

\section{Late complementary feeding}

Delayed introduction of complementary foods is serious problems in some countries especially in Asia Less than one third of infants receive complementary foods by six to nine months in Bangladesh, India and Pakistan (ACC/SCN, 2000).

Nevertheless, late complementary feeding is not a serious problem in sub-Saharan Africa. Statistics show that 23 out of 29 countries have more than $60 \%$ complementary feeding of children 6 -9months. Of these, 14 (50\%) have more than $80 \%$ rate of timely complementary feeding of infants 6-9 months [1].

All the same, it is important to note that initiating complementary feeding loo late could malnourish an infant. At about six months, infants need solid or semi-solid foods to supplement nutrients in breast milk (Population reports, 2003). The late introduction of complementary foods is also disadvantageous because infant growth stops or slows down and lire risk of malnutrition and micronutrient deficiency increases (Monte and Giugliani, 2004).
If a mother does not start to give food until after the age of 6 months, the baby may stop gaining weight at a healthy rate and may become underweight. It also becomes more difficult to persuade the baby to start eating solid foods at a later age. They may want nothing but breast milk or other milk or liquid foods after the age of 1 year and this can cause malnutrition [2].

Inadequate quantity and quality of complementary foods

Providing safe and adequate amounts of foods appropriate for infants and young children is not simple. Complementary foods must be adequately dense in energy and micronutrients to meet the requirements of this age group. They must also be prepared, stored and fed in hygienic conditions to reduce the risk of diarrhea (SCN, 2000).

Food poisoning and nutritional deficiencies are both possible results of poor quality and quantity of complementary foods. Hence these foods should not only be available in sufficient quantities, but also have to be of satisfactory nutritional quality. This is of particular importance in the case of food for young children, for whom food poisoning can have very serious effects and is an important cause of infant mortality. In addition, nutritional deficiencies seriously harm the health and development of children (Doyrain, 1999).

Many of the complementary foods in Africa are based on staples with low protein content such as sweet potatoes or cassava; hence the protein density of these foods is likely to be a limiting factor. The biggest challenge though is meeting micronutrients needs from complementary foods especially key nutrients like iron, zinc and calcium [2].

\section{Knowledge, attitude and practices}

In a study done in Sri Lanka involving 1102 children aged between 0 and 5 years and their caregivers, maternal knowledge and practices regarding safeguarding of the nutritional status of their children was found to be unsatisfactory. Only $19 \%$ of the mothers knew special attention was needed for feeding children during an illness. Of the caregivers, $28 \%$ tried home remedies during illness before the child was taken to a health facility. The percentage of caregivers who immediately took the sick child to the health facility was $51 \%[3]$.

A study in Kenya showed that caregivers saw no reason to have knowledge on early complementary feeding [4]. Lack of awareness of the child's nutritional status and taking care of children were 
found to contribute to malnutrition in a study in Oman. This study reported that caregivers may be in a position to identify the early stages of malnutrition and would only take the children to a clinic when they are severely malnourished [5-11].

\section{Age of complementary feeding}

The optimal age of introduction of complementary foods remains controversial. The appropriate time may represent a compromise between two competing held issues. On one hand, if complementary foods are introduced loo late when breast milk alone no longer meets the infant's energy and nutrient needs, nutrient deficiencies and growth faltering may occur. On the other hand, because these foods are often contaminated with microbial pathogens, premature introduction carries an unnecessary risk of transmission of infection (Brown, 2000).

UNICEF on the other hand maintains that exclusive breastfeeding should go on for about 6 months. According to them, the terminology of " $4-6$ " months is outdated and so is recommending complementary foods from 4 months. But they too again concede that some infants 4 months but not yet 6 months may need early complementation and even go ahead to give 3 indicators for such infants as follows:

1. Child shows interest in semisolid foods e g. reaching for them and shouting

2. Appears hungry after breastfeeding on demand without any limits or

3. Is not gaining weight adequately (UNICEF, 2004).

Research Methodology

Study area

The study will be conducted in Kisii Level 6 Hospital, Kisii County. This is because the hospital caters for Kisii residents as it has many clinics for most diseases. Training sessions are also conducted in the above named hospital and its where breastfeeding and complementary feeding come in.

\section{Administrative boundaries}

Kisii is a city located in south-western Kenya. It is the main urban and commercial center in the Gusii Highlands and the South Nyanza region. A vibrant town, the Kisii municipality has a population of about 400,000, according to 2012 estimates.
The county has seven constituencies namely Kitutu Chache, Nyaribari Chache, Nyaribari Masaba, Bonchari, Bomachoge, Bobasi and South Mugirango.

Population and demographic profile

Based on the 2009 Population and Housing Census, the county population was $1,152,282$ comprising 550,464 males and 601,818 females respectively. This population was projected at $1,226,873$ in 2012 consisting of 536,062 males and 640,811 females. With a growth rate of $2.1 \%$, the population was estimated to be $1,306,652$ in 2015 with 624,171 males and 682,481 females and finally projected to 1,362,779 in 2017 with 650,982 males and 711,797 females.

\section{Climate and Topography}

Kisii County exhibits a highland equatorial climate resulting into a bimodal rainfall pattern with average annual rainfall of $1500 \mathrm{~m}$ with the long rains between March and June while the short rains are received from September to November. The maximum temperatures in the county range between $21 \mathrm{C}-30 \mathrm{C}$ while the minimum temperatures range between $15 \mathrm{C}-20 \mathrm{C}$.

The County is characterized by a hilly topography with several ridges and valleys. It can be divided into three main topographical zones. The first zone cover areas lying below 1,500m above sea level located on the western boundary in Suneka, Marani and Nyamarambe. The second zone covers areas lying between $1500-1800 \mathrm{~m}$ above sea level in western part of Keumbu and Sameta divisions. The third zone covers areas lying above 1800mabove sea level in parts of eastern and southern Keumbu, Masaba and Mosocho. The most notable features are hills and the general slope of the land is from east to west.

\section{Agricultural products}

The main crops produced in Kisii County are maize, bananas, beans, potatoes, tea, sugarcane, coffee and horticultural crops. However due to small land holdings, there will be need to encourage growing of both traditional food crops and horticultural to ensure food security. The acreage under cash crops was approximately 17,800 ha while the area under food crops is about 72,500 ha.

\section{Livestock production}

The main livestock bred in Kisii County were; dairy cattle and zebu, goats, sheep, donkeys, poultry among others. Due to land 
scarcity in the county, there will be need to encourage zero grazing and rearing of grade breeds to increase productivity and balance competing needs for crops and livestock production.

\section{Health facilities}

Kisii County has several health facilities serving the residents of the county. The population will be served by the following Health Facilities: 32 Community Health Units, 84 Dispensaries, 28 Health Centres and 14 Hospitals. On staffing, the county has 41 Doctors and 504 Nurses among other Health Workers.

\section{Education}

As of 2012, there were 904 ECD centers in the county with 1,184 teachers, 467 primary schools with 6,278 teachers and 334 secondary schools with 3,940 teachers. There was a national polytechnic in the county, 7 colleges, one training institution, 1 University College and 8 university campuses of both public and private universities. These institutions will not be adequate to cater for the rising number of youths in pursuits of higher education; therefore there will be need to open up more middle level colleges, polytechnics like Kisii National Polytechnic and universities such as Kisii University and Jaramogi Oginga Odinga University.

\section{Water sources}

In Kisii County, the average distance to the nearest water point is about $2 \mathrm{~km}$. This is as result of the numerous wells, springs and streams roof catchment and boreholes except along the Kisii/ Trans Mara border.

The County has several permanent rivers and streams which drain into Lake Victoria. Kuja which rises from Kiabonyoru hills in Nyamira County is the main river and has adequate water for the development of a mini hydroelectric station. Most of the water is untreated except for the Kisii Water Supply.

\section{Transport and communication}

Kisii County has a good transport and communication network making it easily accessible to the neighboring towns. The roads are well maintained, hence making it accessible from any region in Kenya. The County also has one airstrip at Suneka in Kisii South District which will need to be expanded to allow landing of commercial jets to facilitate movement from the county to major towns like Kisumu, Eldoret, and Nairobi and outside the country.
The county has one major post office in Kisii and ten others in various towns in the county, besides other service providers like G4S, Akamba, Wells Fargo and Easy Coach. It's served by five mobile phone providers namely: Telkom, Orange, YU, Safaricom and Airtel.

\section{Economic activities}

Agriculture, livestock rearing, mining and some fishing activities are the main economic activities in Kisii County. The port of Kisii plays a crucial role in the economy not only Kenya but of other Eastern African countries such as Uganda.

\section{Tourist attraction}

There are potential tourist attraction sites like Tabaka soapstone, river kuja among others which will need to be exploited. Hence there will be need to build tourist hotels especially in Tabaka and provide proper publicity for tourists to have good view.

\section{Religion and traditional culture}

Most people in the county about $80 \%$ are Christians and others are Muslims. Although there are a small number of residents who still adhere to traditional beliefs. Some people believed in medicine men and spirits of their ancestors.

\section{Study design}

The study will be a cross-sectional designed to find out determinants of early complementary feeding practices among children below 6 months attending Kisii County Hospital. This is because the study design will gather the relationship, pattern and links between variables as well as describing the phenomenon without manipulating the variable.

Inclusion and exclusion criteria

Inclusion criteria

- All mothers/caregivers with children below 6 months attending MCH clinic at Kisii County Hospital.

- All mothers/caregivers who will have stayed in the area for more than six months.

\section{Exclusion criteria}

- $\quad$ Caregivers with children over 6 months.

- $\quad$ Caregivers who will have stayed in the area for less than 6 months. 


\section{Study population}

The study population will be children below 6 months with their mothers/caregivers attending Kisii County Hospital.

\section{Sampling procedure}

The sampling method used will be simple random sampling to identify those who will be included in the study whereby, every $5^{\text {th }}$ mother/caregiver with a child below 6 months will be enrolled to represent the entire population.

\section{Sample size}

The sample size will be determined by (Fischer's., et al. 1998) $\mathrm{n}=\mathrm{Z} 2 \mathrm{Pq} / \mathrm{d} 2$

Where:

$\mathrm{n}=$ sample size

$\mathrm{Z}=$ values associated with $95 \%$ confidence intervals usually (1.96)2 $\mathrm{P}=$ Prevalence or proportions in the target population estimated to have the characteristics for example the percentage of children who will be underweight below 6 months.

$\mathrm{q}=1-\mathrm{P}$

$\mathrm{d}=$ the level of statistical significance set monthly (0.05)2

$\mathrm{n}=(1.96) 20.20(1-0.20) /(0.05) 2$

$\mathrm{n}=3.8416 \times 0.20 \times 0.8 / 0.0025$

$\mathrm{n}=0.614656 / 0.0025$

$\mathrm{n}=245$

Data collection instruments

The data collection tools to be used are the self-administered, semi-structured questionnaire and interviews. I will collect the questionnaires after 30 minutes of administration to the caregivers and interviews will be done to illiterate mothers/caregivers.

\section{Validation of data collecting tool}

The questionnaire will be checked by my supervisor who is guiding me in writing the research proposal.

\section{Study limitations}

The study will only assess those mothers/caregivers attending MCH clinic with children below 6 months in Kisii County Hospital and those caregivers who will not attend will be left out.

The study will be confined to only one health facility at Kisii County and only assess the sample size.
Since I am a student, the time allocated for data collection is too short to allow sampling of large population hence sample size of 50 respondents.

\section{Eethical issues}

Ethical clearance will be sort from Kenya Medical Training College (KMTC), National Commission for Science Technology and Innovation (NACOSTI) and Faculty of Public Health, Department of Nutrition and Dietetics and Kisii Level 6 Hospital. Confidentiality will be maintained as the individuals names will not be exposed hence there will be use of numbers and the information will not be used outside the study scope.

\section{Acknowledgement}

I first of all want to thank the Almighty God for giving me the will to do this work and for His grace. I also want to thank my supervisor Madam Arusei for her guidance and commitment during the time of this study. I am also grateful to my colleagues who in one way or another will put their valuable input in the study. I also want to thank the study participants who will take part in the collection of data for the study. Lastly I want to thank my parents for their encouragement throughout the study and for their financial assistance rendered.

\section{Appendices}

\section{Appendix 1: Letter of introduction}

I am Sylviah Moraa Machuki, a student at Kenya Medical Training College studying Community Nutrition in Karen campus. I am undertaking a study on Determinants of Early Complementary Feeding Practices among Children below 6 Months Old in Kisii Level 6 in Kisii County. I am administering this questionnaire so as to aid in data collection. The information given will be made confidential and will only be used for educational purposes.

\section{Appendix 2: Questionnare}

Interview Schedule for the Determinants of early complementary feeding practices among children aged 0-6 months attending MCH Clinic in Kisii Level 6 Hospital.

\section{NOTE}

- All information will be treated with confidentiality.

- $\quad$ Do not write your name on the questionnaire.

- $\quad$ Put a tick on the spaces provided or write where appropriate. 
Date Interviewed

PART A: Socio-demographic and economic characteristics of the respondent

1. What is the age of the respondent (mother/care giver) years?

2. What is your marital status?
1. Single
2. Married
3. Separated
4. Divorced
5. Widowed

3. What is your level of education?
1. Primary
2. Secondary
3. College
4. University
5. Formal education
6. Informal education

4. How many members are in your family?

5 . What is your occupation?
1. Casual worker
2. Self-employed
3. Housewife
4. Formal employment
5. Unemployed

6 . What is your husband's occupation?
1. Casual
2. Self employed
3. Unemployed
4. Formal employment

7. What is your monthly income?

1. Below 5000

2. $5001-10000$

3. Over 10001
PART B: Child socio-demographic characteristics

8. What is the sex of the child?

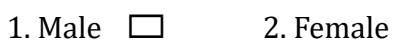

9. What is the age of the child? (Months)

10. First weight_____ ( kg) second weight $(\mathrm{kg})$ Average weight $(\mathrm{kg})$

11. First height (cm) second height $(\mathrm{cm})$ Average height (cm)

\section{PART C: Child feeding practices}

12. did you breastfeed exclusively?

1. Yes

2. No

If No, why?

1. Decided not to breastfeed

2. Breastfeed was not enough

3. Due to health complications

4. Committed in workplace

Others specify.

13. How long does exclusive breastfeeding take?

1. 4 months

2. 6 months

3. Over 6 months

4. Committed in workplace

Others specify.

14. Is the child breastfeeding now?

1. Yes

2. No

If Yes, how frequent do you breastfeed?

1. On demand

2. When with the baby

3. Morning and evening

Others (specify

15. How often is the child fed per day?
1. 2 times
2. 3-4 times
3. 5-6 times
4. On demand 
16. What types of foods are fed to the child?

1. Porridge

2. Mashed potatoes

17. How is the child's food prepared?

1. Boiled

2. Fried separately

3. Scooped from the family pot

Others (specify

18. What utensils do you use to feed the baby?

1. Cup and spoon

2. Feeding bottle

3. Cup, spoon and plate

PART D: Maternal Knowledge, Attitudes and Practices of caregivers

19. Has the child been sick in the last three weeks?

1. Yes

2. No

If yes, what was the illness?

1. Malaria

2. Diarrhea

3. Typhoid

4. Pneumonia

5. Cholera

6. Tuberculosis

7. Other (specify
20. Was treatment sought for the child?
1. Yes
2. No

If yes, where was the child treated?

1. Public health facility

2. Herbal

3. At home

4. Private hospital

5. Others (specify

21 . When your child was sick, how was the appetite?
1. Normal
2. Diminished

If the appetite was diminished, what did you do?

1. Breastfed only

2. Fed and breastfed on demand

3. Gave semi-solid food and breastfed

4. Other (specify

\section{PART E: AGE OF COMPLIMENTARY FEEDING}

22. At what age did you introduce complementary feeding?
1. 0-2 months
2. 3-4 months
3. 4-5 months
4. After 6 months

23. What kind of foods did you give?
1. Water
2. Porridge
3. Mashed foods

\section{Appendix 3}

Workplan

\begin{tabular}{|c|c|c|c|c|c|c|c|}
\hline $\begin{array}{l}\text { Number of } \\
\text { activities }\end{array}$ & Activities & $\begin{array}{c}\text { September } \\
2018\end{array}$ & $\begin{array}{c}\text { October } \\
2018\end{array}$ & $\begin{array}{c}\text { November } \\
2018\end{array}$ & $\begin{array}{c}\text { December } \\
2018\end{array}$ & $\begin{array}{c}\text { January } \\
2019\end{array}$ & $\begin{array}{c}\text { February } \\
2019\end{array}$ \\
\hline 1 & Proposal writing & & & & & & \\
\hline 2 & Presentation of proposal & & & & & & \\
\hline 3 & Data collection & & & & & & \\
\hline 4 & Data analysis & & & & & & \\
\hline 5 & $\begin{array}{l}\text { Presentation and submission of } \\
\text { dissertation }\end{array}$ & & & & & & \\
\hline
\end{tabular}


Appendix 4

Budget

\begin{tabular}{|l|c|c|c|}
\hline ITEM & QUANTITY & $\begin{array}{c}\text { UNIT COST } \\
\text { (KSH.) }\end{array}$ & $\begin{array}{c}\text { TOTAL } \\
\text { (KSH.) }\end{array}$ \\
\hline Transport & 5 & 150 & 750 \\
\hline Lunch & 60 & 16 & 960 \\
\hline $\begin{array}{l}\text { Photocopying and } \\
\text { printing }\end{array}$ & 110 & 8.59 & 945 \\
\hline $\begin{array}{l}\text { Internet services and } \\
\text { Airtime }\end{array}$ & 80 & 35 & 2800 \\
\hline TOTAL & & & 5,455 \\
\hline
\end{tabular}

\section{Bibliography}

1. PAHO/WHO. Guiding Principles for Complementary Feeding of the Breastfed Child. Washington DC: Pan-American Health Organization/World Health Organization; (2002).

2. Burgess A and King FS. Starting Other Foods. In: Nutrition for Developing Countries. 2nd Edition. Oxford University Press, Oxford. (1992): 126-129.

3. Peiris TDR and Wjesinghe DG. Nutritional status of under five year old children and its relationship with maternal nutrition knowledge in Weeraketiye DS Division of Sri Lanka (2010).

4. Leth FCM., et al. "Malnutrition: More than meets the eye can see". East African Medical Journal (2000).

5. Gohar A and Ismail I. Perceptions, attitudes and beliefs in Oman towards nutrition of children under 5years and predisposing causes of Protein energy malnutrition. Ministry of health, Sultanate of Oman, UNICEF (2002).

6. Allen LH and Gillespie SR. "A review of the efficacy and effectiveness of Nutrition Interventions". The Asian Development Bank, Nutrition and Development (2001).

7. Blakely H and Woodward a. Socio-economic status assessing the distribution of health risks by socio-economic position at national and local levels (2004).

8. Ghana Statistical Service and ICF Macro. Ghana DHS report 2008.Calverton, Maryland: GSS and ICF Macro (2009).

9. Infant and Young Child Feeding: Model Chapter for Medical Students and Allied Health Professionals; Geneva World Health Organization, (2009).
10. Nure AS., et al. "Malnutrition of under five children. Evidence from Bangladesh". Asian Journal of medical services (2011).

11. WHO. The optimal duration of exclusive breastfeeding; report on an expert consultation. Geneva World Health Organization; (2001).

\section{Volume 3 Issue 8 August 2019}

(C) All rights are reserved by Abdub Halakhe. 